www.jmscr.igmpublication.org

Impact Factor 5.84

Index Copernicus Value: 83.27

ISSN (e)-2347-176x ISSN (p) 2455-0450

crossref DOI: _https://dx.doi.org/10.18535/jmscr/v5i4.198

Journal Of Medical Science And Clinical Research

\title{
To Assess the Effectiveness of Health Education on Positive Self Esteem in Adolescent Girls in a Semi Urban School Tamil Nadu
}

\author{
Authors \\ Dr N.Kumar, MD, Dr S. Jayaprakash, MD, Dr P. Senthil Kumar, DM Neonatology \\ Coimbatore Medical College Hospital
}

\begin{abstract}
Adolescent girls are most vulnerable group due to biological, hormonal changes and peer pressure. Health education is a part of their school curriculum. Self-esteem is a "set of attitudes and beliefs that one has about self and the surrounding world". This study was aimed to assess the effectiveness of child to child approach in increasing the positive self esteem of adolescent girls in a semi urban school setting in western Tamil Nadu. This study was done as an experimental design, a randomized control study which was carried out among adolescent girls 10-15 years in a semi urban school. 220 students were selected based on stratified random sampling technique and all students' socio demographic datas were collected. Their base level self esteem score was assessed by Rosenberg's self esteem scale and Robson self esteem questionnaire. Then the students randomly allotted to study and control groups. After that a teaching programme of 45 minutes was conducted as lecture and small group discussions, work shop method with a training module. After 1 week of teaching programme their self esteem scores were assessed again for both groups with the same scale. The data were analyzed through SPSS, version 14, using Mann-Whitney test, Chi-square test, Wilcoxon, ANOVA. Before the educational intervention, the frequency distribution of girls' self-esteem in the study and control groups did not differ significantly from each other ( $p>0.5)$. The mean post test total self-esteem scores in the study groups compared to control groups, was significantly different $(p<0.001)$. Before the intervention, the mean for self-esteem in the study groups was $45.70 \pm 12.80$ but in the post-test the mean increased to 66.23 \pm 14.52 . The statistical analysis showed no significant difference between the study and control groups concerning the students' demographic variables. After the intervention in the study group, the general self-esteem and academic self-esteem showed the greatest change and family self-esteem had the lowest change during the study. In control group no much difference is observed in general and academic self esteem but family self esteem increased marginally $(P>0.452)$. This study showed that health education resulted in a significant increase in total self-esteem. National and international studies have confirmed the efficacy of peer-led approach. This approach is an effective strategy for HIV prevention, preventing smoking, breast self-examination training, and parenting in the context of children behavioural disorder. Here we tried a child to child approach and this is also found to be useful. A special trainer in each school can do this teaching learning programme with the help of a health care with a pre formed training module as in our study. It is concluded that child to child approach is also an effective way of increasing positive self esteem in adolescents.

Keywords: Self esteem, Adolescents, Education.
\end{abstract}




\section{Introduction}

Adolescent girls are most vulnerable group due to biological, hormonal changes and peer pressure. Adolescence is a critical period of physical, psychological, emotional, behavioural and cognitive changes which is the determinants of health in adulthood, so protection of adolescents in this period appears vital and essential. They need health education in various aspects like personal hygiene, menstrual hygiene, good nutrition, vaccines, and psychosocial issues. Health education is a part of their school curriculum. But getting trained teachers in health education is difficult. A special teacher is needed in each high and higher secondary school to address the needs of an adolescent girl including health related issues, psycho social issues. The present scenario of adolescents clearly shows that the condition of our youth has significantly deteriorated. Recent studies show that there is significant rise in the problems faced by the adolescents for example, serious emotional disturbances has increased (WHO, 2001), increased sexual activity in schools, rise in AIDS cases in India \& greater use of alcohol consumption has been found (BSS, 2007). Apart from the above, use of heavy drugs and youth drop outs have also increased in the recent years (UNICEF, 2001). All these studies clearly illustrate the increase in aggressiveness, suicidal cases, drug use, and depressive cases among adolescents. This gives us the clear image of the struggles that adolescents go through, the problems they face. So providing an experience that would strengthen adolescent's coping abilities to counter environmental stress and disadvantages with which they sometimes have to cope with while experiencing is an essential need. A key aspect of human development - as important to basic survival as intellect - is the acquisition of socio-cognitive and emotional coping skills. This has been shown to have impact on behaviours. For more than a decade, research on interventions that address these specific skill areas has shown their effectiveness in promoting desirable behaviours, such as sociability, improved communication, effective decision making and conflict resolution, and preventing negative or high-risk behaviours, such as use of tobacco, alcohol and other drugs, unsafe sex, and violence.

Self-esteem is an "individual's positive or negative attitude toward the self as a totality"1, and positive self-esteem is a key aspect in the development of a healthy personality. Self-esteem is one of the fundamental elements of character and important determinant of balance and selftranscendence. It is also an essential component of good health. Self-esteem is a "set of attitudes and beliefs that one has about self and the surrounding world". From Pope's viewpoint, “everyone's selfesteem based on a combination of objective information about each person's and subjective values, for which information is allowed, will be built" 4 . An individual's level of self-esteem can affect all areas of his/her life. Youth with high levels of self-esteem tend to avoid a broad array of emotional, behavioural and social problems that afflict those with lower levels. High self-esteem has been linked to better relationships, higher academic achievement, and better coping skills. Low self-esteem has become a significant issue within culture today, affecting a large number of students and resulting in many negative outcomes. Low self-esteem has been linked with susceptibility to peer-pressure and peer-influence, body dissatisfaction in adolescent girls, mental health issues, eating disorders, and higher rates of sexual risk-taking, peer pressure. The views of family and friends and peer pressure play a significant role in the life of adolescents and the decisions they make and is an even larger issue in those with poor self- esteem.

Ata et al. (2007) found that adolescents with low self-esteem are more vulnerable to peer-pressure and are more likely to internalize the messages from others. Those with lower self-esteem are more likely to yield to others and are more easily influenced by others. One reason for this may be that adolescents with lower self-esteem usually have fewer friends and report being lonelier. This 
can lead to drug use, sexual behaviour, breaking the law and other peer influenced poor choices. Family pressure has also been found to be a predictive factor in body image and eating behaviours in adolescents. Low self-esteem is the most critical problem that adolescents face today in the field of mental health ${ }^{6}$. According to the existing evidence, low self-esteem in adolescents is related to negative consequences such as antisocial behaviour and delinquency, academic failure, aggression, and suicide. In contrast, high self-esteem in adolescents is associated with happiness, self-confidence, academic achievement, community involvement, interpersonal relationships and mental health. Self-esteem is the cognitive schema and acquisitive and learning phenomenon. Social institutions such as family, school, peers and the media have an important role in the development of self-esteem. School, as the first official status of social experience of adolescents, has an important role in the process of social development and is a decent environment for training programs in the field of self-esteem. School-based programs, using respondent-driven and interactive techniques, have an effective role in the improvident of self-esteem.

Paxton, Eisenberg, \& Nuemark- Sztainer (2006) reports that $24 \%-46 \%$ of adolescent girls reportedly having body dissatisfaction, and this problem reaches across many ages. Dohnt \& Tiggerman state that "a number of studies have now identified there is a desire for thinness in 6 year-old girls". The results can be devastating when steps are not taken to increase the selfesteem of adolescent girls. Many researched interventions have shown that improvements in self-esteem can be achieved. According to Haney \& Durlak's study, "It is possible to significantly improve children's and adolescents levels of $\mathrm{SE} / \mathrm{SC}$ [self-esteem/self-concept] and to obtain concomitant positive changes in other areas of adjustment". Working to improve self-esteem can also reduce body dissatisfaction among adolescents (Paxton et al., 2006). To provide the most help for their students, it is imperative that school counsellors provide research based program interventions to help improve the selfesteem and body image of adolescent girls. This study is aimed to assess the effectiveness of child to child approach in increasing the positive self esteem of adolescent girls in a semi urban school setting in western Tamil Nadu.

Aim of the study: effectiveness of health education in adolescent girls

Primary objective: To assess the effectiveness of health education on positive self esteem in adolescent school children in a semi urban school

Secondary objective: To find out the association between pre test knowledge score in first group and second group regarding positive self esteem with selected socio demographic variables

\section{Operational definitions}

Effectiveness: here it refers to the extent to which teaching program on positive self esteem has achieved the desired effect as evidenced by gain in post test knowledge.

Child to child approach: it refers to one who is exposed to the teaching by the investigator to reach out to other children by imparting knowledge on positive self esteem

Positive self esteem: it refers to the sense of contentment and self acceptance that result from a person's appraisal of his own worth, significance, attractiveness, competence and ability to satisfy his aspirations.

\section{Methodology}

Design: Randomized control study

Setting: higher secondary girl school in semi urban Coimbatore, West Tamil Nadu

Target population: adolescent girls in the age group between 10-15 years

Sample size: 220 calculated based on previous studies $^{2}$.

\section{Sampling technique:}

This study is an educational randomized controlled study. The sample consisted of 220 female second graders in secondary schools in 
semi urban school. A stratified random sampling method was used equal number in varies age group were taken. The selected students in each class were randomly allocated to the study and control groups. Finally, 110 students were in the study group and 110 in the control group; in total, 220 students participated in the study.

Inclusion criteria: Adolescent girls in the age group between 10-15 years

Exclusion criteria: Any girl with medical illness are excluded

Data collection technique: In person

Tool: self structured demographic proforma

\section{Standardized self esteem scale:}

1.Rosenberg's self esteem scale

2. Robson self esteem questionnaire

\section{Hypothesis/flow:}

- Assess the pre test knowledge on positive self esteem between first and second group adolescent girls.

- Administer health education on positive self esteem in first group

- Assess post test knowledge on both groups

- To evaluate the effectiveness of child to child approach to positive self esteem between first group and second group

$\mathrm{H}-\mathrm{I}$ : There is a difference between mean pre test and post test score in first group $(\mathrm{P}=<0.05)$

H-II: There is a difference between mean post test score of group one and group two at 0.05 level of significance

H-III: there is an association between pre test knowledge score regarding positive self esteem in adolescent girls with selected socio demographic variables in first group and second group at 0.05 level $\mathrm{f}$ significance

Manoeuvre: The present study is an educational controlled study. 220 female students in the second grade were selected with the stratified randomization sampling method. The selected students were randomly assigned to study and control groups. The data were collected before, in the control and experimental group, using proforma and self esteem score was assessed by applying Rosenberg's self esteem scale and
Robson self esteem questionnaire. The educational intervention in the experimental group was a teaching programme 45 minutes, using lectures, discussion techniques in small groups (the group work, role play and group play) and a training manual. Post test measuring was performed 1 week after the program was finished. The data were analyzed through SPSS, version 14, using Mann-Whitney test, Chi-square test, Wilcoxon. To compare the differences in self-esteem between groups, analysis of variance (ANOVA) was use.

Results: The results showed that the mean of total self-esteem scores in the study groups compared to that in the control groups, one weeks after the teaching intervention was significantly different $(p<0.001)$. Before the intervention, the mean for self-esteem in the study groups was $45.70 \pm 12.80$ but in the post-test the mean increased to $66.23 \pm 14.52$. Before the educational intervention, the frequency distribution of girls' self-esteem in the study and control groups did not differ significantly from each other $(\mathrm{p}=0.337)$. But one week after the intervention, a significant increase was observed between the two groups $(\mathrm{p}<0.001)$.

The statistical analysis showed no significant difference between the study and control groups concerning the students' demographic variables. The students' mean age in the study and control groups was $12.55 \pm 0.45$ and $12.78 \pm 0.54$, respectively. $31.4 \%$ of the students in the study and $29.15 \%$ of the students in the control groups were the second child of the family. In the present study, the fathers of $25.2 \%$ of the students in the study and the fathers of $26.5 \%$ of those in the control group had university education, and their mothers had secondary school education and degree [experimental (34.3\%), and controls $(32.6 \%)]$.

Also, the fathers of $18.5 \%$ of the students in the experimental and the fathers of $17.6 \%$ of those in the control group had elementary education. Their mothers had the same level of education [the experimental group (11.3\%) and the control group (12.4\%)].A higher percentage of fathers in the experimental $(37.2 \%)$ and control groups (36\%) 
were self employed, $32.01 \%$ in study and $34.6 \%$ in control were salaried and a smaller percentage of them in the study (4.5\%) and control (4.6\%) groups were unemployed, Most mothers in the experimental $(82.3 \%)$ and control groups $(85.6 \%)$ were housewives and the rest were employed [study (16.2\%) and control groups (17.2\%)].

In the present study, after the educational intervention in the study group, the general selfesteem and academic self-esteem showed the greatest change and family self-esteem had the lowest change during the study. In control group no much difference is observed in general and academic self esteem but family self esteem increased marginally ( $\mathrm{P}>0.452)$.

\section{Discussion}

This study showed that health education resulted in a significant increase in total self-esteem in female students' of the study group one week after the intervention. National and international studies have confirmed the efficacy of peer-led approach. This approach is an effective strategy for HIV prevention, preventing smoking, breast selfexamination training, and parenting in the context of children behavioural disorder. Here we tried a child to child approach and this is also found to be useful. A special trainer in each school can do this teaching learning programme with the help of a health care with a pre formed training module as in our study. In the present study, the students' knowledge increased significantly after the intervention indicating that the implemented training program could meet the students' needs considerably. Acquisitive and learning of selfesteem is also supported by this study. Also, the results of the present study showed that the selfesteem subsets (general, body, social and academic), except for the family self-esteem had a significant increase after the training intervention. According to the findings of this study, selfesteem is influenced by body image component. In this study, the educators, due to their dominance over the students, could make positive changes concerning the students' body image and thus significantly increase their body self-esteems. Findings in other studies approved that low selfesteem in body dissatisfaction is important and necessary. Paxton and Clay et al in their studies concluded that educational intervention can help to rebuild bad image of female body formed. Katibaei and et.al showed in their study that have a good body image and reinforcing physical abilities is one of the key elements of self-esteem in adolescents and training have a special role in forming this good image. In the present study, participating in group counselling sessions and interaction with peers may also reinforce the social self-esteem. Dalgas and et-al in their study about the effects of intervention programs on the self-esteem of school-age students showed that after the educational intervention, general selfesteem and social self-esteem of students have increased considerably. In this study, after general self-esteem, academic self-esteem in the experimental group showed the greatest increase. The positive effect of education on promoting self-esteem, relaxation, behavioural changes and academic achievement has been proven in several studies.

\section{Ethical Consideration}

CEO of the district approval was obtained and after explanation about the study, the participants gave oral consent. Also participants in the study were assured that the questionnaire will be anonymous and all information will remain confidential. Upon completion of the study, in order to maintain the ethical considerations, we provided the control group with the key points of the educational program.

\section{Conclusion}

The findings of this research could help the educators involved in the education department or the counselling centres on adolescent health to increase self-esteem. The role of self-esteem and its positive role in the performance of students in the academic and social life confirm the significance of this study. 


\section{Reference}

1. Global Self-Esteem and Specific SelfEsteem: Different Concepts, Different Outcomes Author(s): Morris Rosenberg, Carmi Schooler, Carrie Schoenbach, Florence osenberg Source: American Sociological Review, Vol. 60, No. 1 (Feb., 1995), pp. 141-156

2. Indian Journal Of Applied Research: Volume : 4 | Issue : 6 | June 2014 | A study on the Self esteem of Adolescent College students. Priya.V, Dr. K. Muralidharan, Research Scholar, Social Work, Karpagam University Coimbatore $-641021$

3. J Adv Med Educ Prof. 2014 Apr; 2(2): 63-70. The effects of a peer-led training program on female students' self-esteem in public secondary schools in Shiraz Mohammad Hossein Kaveh, ${ }^{1 *}$ Maryam Hesampour, ${ }^{2}$ Leila Ghahremani, ${ }^{2}$ And Hamid Reza Tabatabaee ${ }^{3}$

4. Amin Shokravi F, Memarian R, Hajizadeh E, Moshki M. The roll of enhancing self esteem educational program on self-esteem promotion of the girl students in Tehran primary schools. Ofoghe-Danesh. 2008;13(4):74-81. Persian.

5. Biro FM, Striegel-Moore RH, Franko DL, Padgett J, Bean JA. Self-esteem in adolescent females. Journal of Adolescent Health. 2006; 39 (4):501-7.

6. Turkashv and R, Kermanshahi $\mathrm{S}$, Azadfalah P. The effect of educational group therapy plan on self-esteem rate in adolescent girls. Zahedan J Res Med Sci (ZJRMS) 2011;13(3):30-4.

7. Peixoto F, Almeida LS. Self-concept, self-esteem and academic achievement: strategies for maintaining self-esteem in students experiencing academic failure. European Journal of Psychology of Education. 2010;25(2): 157-75.
8. Jalali D, Nazari A. Effects of social learning model training on self-esteem, self-confidence, self assertiveness and academic achievement in third grade students of intermediary schools. Journal of Research in Behavioural Sciences. 2009;7(1):1. Persian.

9. Dalgas Pelish P. Effects of a self-esteem intervention program on school-age children. Pediatric nursing. 2006;32(4): 341-8.

10. Nouri M. The impact of peer-based educational approaches on girls' physical practice of pubertal health. Arak Medical University Journal. 2010;12(4):129-35. Persian.

11. Malak A, Bektash M, Turgay A, Tuna A, Ekti R. Effects of peer education, social support and self esteem on breast self examination performance and knowledge level. Asian Pacific J Cancer Prev. 2009;10(1):605-8]

12. Xiaoling X, Yan L. Peer Education for Health-Enhancing, a motivational project for immigrant women to increase the level of physical activity in Ishøj Kulturhus of Denmark. Ishøj Kulturhus (Denmark): Clinical Dietician in Metropolitan University College; 2012.

13. Bulduk S, Erdogan S. The effects of peer education on reduction of the HIV/sexually transmitted infection risk behaviors among Turkish university students. Journal of the Association of Nurses in AIDS Care. 2012;23(3):23343

14. Peykari N, Tehrani FR, Malekafzali H, Hashemi Z, Djalalinia S. An experience of peer education model among medical science university students in Iran. Iranian journal of public health. 2011;40(1):57.

15. Taghdisi M, Noori SistanI, Merghati KE, Hoseini F, Asgharnejad FA. Impact peer education approach on knowledge and 
practice about Mental Health of Adolescent Girls. Toloo-E-Behdasht. 2012; 10(3): 92-105.

16. Mazaheri A, Baghban I, Fatehzadeh M. Effects of self esteem group training on students' social adjustment. Daneshvar Raftar. 2006;13(16):49-56.

17. Borras L, Boucherie M, Mohr S, Lecomte T, Perroud N, Huguelet P. Increasing self-esteem: efficacy of a group intervention for individuals with severe mental disorders. European Psychiatry. 2009;24 (5):307-16.

18. Clay D, Vignoles V, Dittmar H. Body Image and Self-Esteem among Adolescent Girls: Testing the Influence of Sociocultural Factors. Journal of Research on Adolescence. 2006;15(4):451-7.1

19. Katibaei J, Ganjavi L, Hasanbeiki Z, Ghanbari S, Seyed Mousavi P. An Effectiveness Evaluation of Cognitive Reconstructing Training on Reform of

\section{Annexure: I}

\section{Proforma:}

1. Name:

2. Age:

3. Sex:

4. Class:

5. Religion: $\mathrm{H}(), \mathrm{M}(), \mathrm{C}(\mathrm{)})$, Other( )

6. No of siblings: $1,2,3,>3$

7. Birth order: I, II, III, >III

8. Father occupation: Govt, Pvt, Self, Daily wages, unemployed

9. Mother occupation: Govt, Pvt, Self, Daily wages, House wife

10. Father Education: illiterate, primary, secondary, graduate, professional

11. Mother education: illiterate, primary, secondary, graduate, professional

12. Type of family: nuclear, joint, extended family

13. Family Income: < 5000, 5000-10000,

14. Area of residence: rural, semi urban, urban
Negative Body Image in Girls Adolescents. Journal of Psychology. 2011;14(1):357-69.

20. Robins RW, Trzesniewski KH. Selfesteem development across the lifespan. Current Directions in Psychological Science. 2005;14(3):158-62.

21. Effect of a parenting education program on girls' life satisfaction in governmental guidance schools of Shiraz.[J Adv Med Educ Prof. 2014]

22. Effect of educational intervention on physical activity-related knowledge, attitude and behavior of among firstgrade students of male high schools.[J Educ Health Promot. 2013]

23. The effects of a peer-led training program on female students' self-esteem in public secondary schools in Shiraz Journal of Advances in Medical Education \&\#x0026; Professionalism. 2014 Apr; 2(2)63 
Annexure II

Assessment of positive self esteem among adolescent girls

Rosenberg's self esteem scale

\begin{tabular}{|c|c|c|c|c|c|}
\hline S.No & STATEMENT & Strongly agree & Agree & Disagree & $\begin{array}{l}\text { Strongly } \\
\text { disagree }\end{array}$ \\
\hline 1 & $\begin{array}{l}\text { I feel that I'm a person of } \\
\text { worth at least on an equal } \\
\text { plane with others }\end{array}$ & & & & \\
\hline 2 & $\begin{array}{l}\text { I feel that i have a number } \\
\text { of good qualities }\end{array}$ & & & & \\
\hline 3 & $\begin{array}{l}\text { All in all, I am inclined to } \\
\text { feel that I am a Failure }\end{array}$ & & & & \\
\hline 4 & $\begin{array}{l}\text { I am able to do things as } \\
\text { well as most other people }\end{array}$ & & & & \\
\hline 5 & $\begin{array}{l}\text { I feel that I don't have } \\
\text { much to be proud off }\end{array}$ & & & & \\
\hline 6 & $\begin{array}{l}\text { I take a positive attitude } \\
\text { towards myself }\end{array}$ & & & & \\
\hline 7 & $\begin{array}{l}\text { On the whole I am } \\
\text { satisfied with myself }\end{array}$ & & & & \\
\hline 8 & $\begin{array}{l}\text { I wish I could have more } \\
\text { respect for myself }\end{array}$ & & & & \\
\hline 9 & $\begin{array}{l}\text { I certainly feel useless at } \\
\text { times }\end{array}$ & & & & \\
\hline 10 & $\begin{array}{l}\text { At times I think I am no } \\
\text { good at all }\end{array}$ & & & & \\
\hline
\end{tabular}

$1,2,4,6,7=3,2,1,0$.

$3,5,8,9,10=0,1,2,3$. Scale range from $0-30$. Between $15-25$ is within normal range,

below 15 suggest low self esteem

\section{Robson self esteem questionnaire- RSEQ}

The larger the value, the lower the self esteem

* Response: 0- strongly disagree, 1-disagree, 2slightly disagree, 3- undecided, 4-slighly agree, 5agree, 6- strongly agree (negative response)

** Response:6- strongly disagree, 5-disagree, 4slightly disagree, 3- undecided, 2-slighly agree, 1agree,0- strongly agree (positive response)

** I am not embarrassed to let people know my opinions

* I seem to be very unlucky

* I can never seem to achieve anything worth while

* I do not care what happens to me

** I Have control over my own life

**Most people find me reasonably attractive

** I am glad I am who I am

** I am a reliable person

*It would be boring if I talked about myself

*When I am successful there is usually a lot of luck involved
**I have a pleasant personality

*I often feel humiliated

**I can usually make my mind up and stick to it

*Everyone else seems much more confident and contended than me

*I often worry about what other people are thinking about me

**There is a lot of truth in the saying "What will be, will be"

*I look awful these days

**If I really try I can overcome most of my problems

*It's pretty tough to be me

**I feel emotionally mature

*When people criticize me I often feel helpless and second rate

*When progress is difficult, I often find myself thinking it's just not worth the effort

**I can like myself even when others don't

**Those who know me well are fond of me

144 score. 


\section{Annexure III}

Planned Teaching programme:

Topic: positive self esteem

Duration: $45 \mathrm{~min}$

Method of teaching: small group lecture and group activity

Teaching aids: PPT, charts

Central objective: on completion of the health education, the adolescent girl will acquire knowledge on various aspects on positive self esteem and make healthy choices in life.

Specific objectives: On completion of the session the adolescent girls will be able to

- Define self esteem

- Enumerate special features of the three stages of adolescence in girls

- Enlist morphological changes in girls

- List down psychological changes

- Discuss how self esteem is built and destroyed

- Enumerate the advantage of a positive self esteem

- Discuss tips for positive self esteem

- Explain how to identify people with a healthy level of self esteem

- Get to know one self

- Make healthy choices as adolescence and in their adult lives

- Inform and support other adolescent girls to do the same

\section{Introduction}

We all have a mental picture of who we are, how we look, what we're good at, and what our weaknesses might be. We develop this picture over time, starting when we're very young kids. The term self-image is used to refer to a person's mental picture of himself or herself. A lot of our self-image is based on interactions we have with other people and our life experiences. This mental picture (our self - image) contributes to our selfesteem.

Self-esteem is all about how much we feel valued, loved, accepted, and thought well of by others-and how much we value, love, and accept ourselves.
People with healthy self-esteem are able to feel good about themselves, appreciate their own worth, and take pride in their abilities, skills, and accomplishments. People with low self-esteem may feel as if no one will like them or accept them or that they can't do well in anything.

\section{Self-esteem}

Self esteem is a term used in psychology to reflect a person's overall evaluation or appraisal of his or her own worth. Eg - I am competent. I am worthy. Positive self-concept

An idea of the self constructed from the beliefs one holds about the responses to others.

Mental image or perception is that one has of oneself.

Self-concept: Picture or perception of ourselves

Self Esteem: Feelings we have about ourselves

\section{Adolescence - Self Estem}

Adolescence begins with the onset of puberty; defined by the UNICEF, as "the sequence of events by which the individual is transformed into a young adult by a series of biological changes ' It is during this period that secondary sex characteristics develop.

Special Features of the Threee Tages of Adolescence

Early adolescence (10-13years)

Growth spurts and secondary sex characters.

Middle adolescence (14-16years)

Separate identity from parents, new rapport with peer group and opposite sex and experimentation.

Late adolescence (17-20years)

Established adult physical characters, distinct identity and opinions and ideas.

\section{Order of Morphological Changes in Girls}

- Accelerated gain in weight and height.

- Breast changes like pigmentation of areola and enlargement of breast tissue and nipple.

- Increase in pelvic girth.

- Appearance of public hair. 
- Onset of menstruation (menarche). The first bleed occurs usually 2 years after the first manifestation of puberty.

- A abrupt slowing of gain in weight.

\section{Phychological Changes}

- Development of "'identity with peer groups,

- Community,

- Exploration of own and other's bodies as also potentials,

- Autonomy from parents,

- Sex role identity,

- Morality and career choice.

Failure to accomplish these tasks may cause psychological problems.

\section{How is Self-Esteem Build \& Destroyed Building}

- Find a good role model

- Praise \& compliments

- Focus on the positive

- Keep criticism to a minimum

- Set \& achieve goals

\section{Destroyed}

- Comparing yourself to others

- Putting yourself down

- Drug abuse

\section{Advantages of a Positive Self Esteem}

- Believes in self

- Willing to try new things

- Appreciates life

- Changes the bad

- Leader to other

- Accepts t others

- Is not a threat to others?

- Doesn't submit to peer pressure.

\section{Tips for Building Self Esteem}

1. Identify with people, books, videos, television shows, etc., that built your selfesteem

2. Think positively

3. Set and achieve goals

4. Do something challenging each day

5. Look your best

6. Eat correctly
7. Do something for someone else

8. Learn a new skill

9. "Observe self-concept people

10. Handle things one at a time

11. Use criticism constructively

12. Ask for help - take advantage of learning opportunities

13. Improve your personal living space

14. Allow personal growth time each day

15. Post self-improvement reminders in obvious places

16. Do not say negative things about yourself

17. Reward yourself often

18. List your accomplishments each evening

19. Volunteer to share your skills with others

\section{People with a Healthy Level of Self-Esteem}

- Firmly believe in certain values and principles.

- Are able to act according to what they think to be the best choice, trusting their own judgment, and not feeling guilty when others don't like their choice.

- Have positive attitude towards oneself

- Do not lose time worrying excessively about what happened in the past, nor about what could happen in the future. They learn from the past and plan for the future, but live in the present intensely.

- Emotionally mature

- Fully trust in their capacity to solve problems, not hesitating after failures and difficulties. They ask others for help when they need it.

- Consider self, equal in dignity to others, rather than inferior or superior, while accepting differences in certain talents.

- Not feel embarrassed to let people know ones opinions.

- Glad to be the person she is.

- Firmly believes that she is reliable.

- Resist manipulation; collaborate with others only if it seems appropriate and convenient 
- Accepts ones potentialities and good qualities.

- Admit and accept different internal feelings and drives, either positive or negative, revealing those drives to others only when they choose.

- Are able to enjoy a great variety of activities.

- Are sensitive to feelings and needs of others; respect generally accepted social rules, and claim no right or desire to prosper at others 'expense.

- Take responsibility for one's own life.

Task - 1

Get a nice notebook and, at the end of each day, note down 5 positive thoughts about yourself and your experience. This helps you continually focus on the positive, which can otherwise easily pass by, unappreciated. What you focus on grows, so turn your attention to the positive self esteem.

Task - 2

Use daily affirmations to help your thinking in a more positive frame of mind. Although it may seem false at first, it helps you focus on the positive and practice thinking and saying good things about yourself. For example, "I like and accept myself just how I am" or "I am someone special and I believe in myself."

What are your first realistic steps towards achieving that life? Set goals and take action towards creating the life you want

This Year I will:

This month I will:

This week I will:

\section{Conclusion}

There are two different people in the world. One that says "I wish I had" and the one that says "I'm glad I did". Remember you can have anything in this world if you just believe in yourself. 